\title{
Contract FDF Manufacturing
}

National Cancer Institute

\section{Source}

National Cancer Institute. Contract FDF Manufacturing. NCI Thesaurus. Code C132491.

Manufacturing of a part or all of final dosage form (FDF) that takes place in a contract facility and the contract facility is not identified in an approved ANDA owned by that facility or its affiliates. 